\title{
Potency and Stability of Intradermal Capsaicin: Implications for Use as a Human Model of Pain in Multicenter Clinical Trials
}

\section{Pavan Balabathula ${ }^{1 *}$, Himanshu Bhattacharjee ${ }^{1}$, Laura A Thoma ${ }^{1}$, Robert J Nolly ${ }^{1}$, Frank P Horton', Gwendolyn D Stornes ${ }^{1}$, Jim Y Wan ${ }^{2}$, lan} M Brooks ${ }^{3}$, Gloria A Bachmann ${ }^{4}$, David C Foster ${ }^{5}$ and Candace S Brown ${ }^{6}$

${ }^{1}$ Plough Center for Sterile Drug Delivery Systems, College of Pharmacy, University of Tennessee Health Science Center, Memphis TN, USA

${ }^{2}$ Department of Preventive Medicine, University of Tennessee Health Science Center, Memphis, TN, USA

${ }^{3}$ Biomedical Informatics, University of Tennessee Health Science Center, Memphis TN, USA

${ }^{4}$ University Medical Dental School of New Jersey-Robert Wood Johnson, New Brunswick NJ, USA

${ }^{5}$ Department of Obstetrics and Gynecology, University of Rochester School of Medicine and Dentistry, Rochester NY, USA

${ }^{6}$ Department of Clinical Pharmacy, University of Tennessee Health Science Center, Memphis TN, USA

\begin{abstract}
Intradermally injected capsaicin has been used extensively both as a human pain model and to assess analgesic efficacy. Factors such as dose, formulation, route, and site are known to affect its sensitivity. We determined whether potency and stability of capsaicin solutions were further sources of variability when following strict manufacturing guidelines. Capsaicin solution $(1.0 \mathrm{mg} / \mathrm{mL}$ ) was prepared according to Current Good Manufacturing Practice (cGMP) guidelines and aseptically filled into sterile amber borosilicate vials and stored at $5^{\circ} \mathrm{C}, 25^{\circ} \mathrm{C}$, and $30^{\circ} \mathrm{C}$. All samples were analyzed at one, three, six, and twelve months. Chemical stability was determined using HPLC and physical stability was evaluated by visual inspection of color changes, clarity, particulate matter, and product/ container closure abnormalities during each sampling time. Capsaicin intradermal injection was found to be sterile and retained $95 \%$ of the initial concentration for at least one year, regardless of studied storage temperatures $(P<0.0001)$. Visual inspection indicated no changes in color, clarity, particulate matter, and product/ container closure abnormalities in all samples. These data show that capsaicin solutions $(1.0 \mathrm{mg} / \mathrm{mL})$ maintain their potency and stability over one year when manufactured according to cGMP guidelines. These results suggest that in clinical trials manufacturing of capsaicin solutions is recommended over extemporaneous compounding.
\end{abstract}

Keywords: Capsaicin; Human pain model; Intradermal; Variability; Manufacture

\section{Introduction}

Inflammatory substances, such as capsaicin, have been used experimentally to measure clinical pain dimensions of hyperalgesia and allodynia, characteristics of central sensitization [1-5]. Following intradermal and topical application, capsaicin binds to the vanilloid receptor VR-1 and initiates nociceptive C-fiber activity [6,7]. Within a period of seconds to minutes enhanced cutaneous sensitivity (punctuate hyperalgesia and dynamic allodynia) develop beyond the region of initial pain and characterize alterations in central nervous system activity called central sensitization.

Capsaicin-induced cutaneous sensitivity has been observed in a number of painful conditions, including post herpetic neuralgia [8], complex regional pain syndrome [9], fibromyalgia [10,11], rheumatoid arthritis [12], vulvodynia [13], unilateral sciatica [14], and multiple chemical sensitivity [15]. These disorders may represent a common dysfunction in central processing of pain stimuli [16]. Thus, capsaicin may represent an important aid in the study of pain mechanisms and to demonstrate the analgesic potential of new compounds.

However, the sensitivity of capsaicin models has been limited by significant variability in measuring allodynia and hyperalgesia. Capsaicin sensitivity has been shown to be influenced by skin temperature [2,17], arm dominance [18,19], limb position [18] and site of injection $[17,18]$. More recent studies show that administration route [17-19], dose [1,4,19-21], and formulation [18] also produce variability. Methods that insure uniformity are crucial to the understanding of pain mechanisms and for evaluating analgesic efficacy.

The intradermal route of administration is most commonly used in pain studies and has more consistent effects on allodynia and hyperalgesia than topical application [17]. The enhanced reliability of intradermal administration is most likely due to the dose dependent effects of capsaicin, where the magnitude and duration of pain have been shown to have a linear relationship from 1 to $100 \mu \mathrm{g}$ [4]. At present, only two studies have evaluated the potency and stability of stored capsaicin solutions, even though these factors may directly affect capsaicin concentrations. In these studies by the same research laboratory, very low concentrations of capsaicin were prepared to study cough reactivity and antitussive efficacy with aerosol administration $[22,23]$. They found concentrations were less than predicted, were enhanced by addition of an emulsifier, and varied according to temperature, light exposure, and concentration over a 12-month period. These results have not been replicated at the higher concentrations used for intradermal administration in chronic pain models.

Most chronic pain studies have relied on extemporaneous compounding of capsaicin. A standardized intradermal formulation for centralized distribution would be advantageous in multicenter clinical trials, where the accuracy of pain measurement is crucial, and where compounding facilities and techniques may vary among clinical sites. Our goal was to determine the potency of a capsaicin solution

*Corresponding author: Pavan Balabathula, 26 S Dunlap St. Suite 214 Memphis TN 38163, USA, Tel: +001-901-448-4637; Fax: +001-901-448-6092; E-mail pbalabat@uthsc.edu

Received October 11, 2013; Accepted November 30, 2013; Published December 10, 2013

Citation: Balabathula P, Bhattacharjee H, Thoma LA, Nolly RJ, Horton FP, et al (2013) Potency and Stability of Intradermal Capsaicin: Implications for Use as a Human Model of Pain in Multicenter Clinical Trials. Clin Exp Pharmacol 3: 142. doi:10.4172/2161-1459.1000142

Copyright: (c) 2013 Balabathula P, et al. This is an open-access article distributed under the terms of the Creative Commons Attribution License, which permits unrestricted use, distribution, and reproduction in any medium, provided the original author and source are credited. 
for intradermal administration and its stability over time at various temperatures.

\section{Materials and Methods}

\section{Materials}

Capsaicin USP analytical standard sample was obtained from USP (Rockville, MD, USA) and High Performance Liquid Chromatography (HPLC) grade methanol and water were obtained from Fisher (Pittsburg, PA, USA). Capsaicin solution was manufactured using capsaicin ( $\geq 95 \%$ purity) obtained from Sigma-Aldrich (St. Louis, MO, USA) dissolved in polysorbate $80 \mathrm{NF}$ (Fluka, St. Louis, MO, USA), and $0.9 \%$ sodium chloride solution (Hospira Inc., Lake Forest, IL, USA).

\section{Preparation of $0.1 \%$ capsaicin solution}

The capsaicin solution was prepared according to the method used by Simone et al. [4], where a dose-response relationship was observed in early pain studies and according to previous methods [13]. Capsaicin solution ( $0.1 \%$ capsaicin, $7.5 \%$ polysorbate 80 , and $0.9 \%$ sodium chloride solution q.s.t $100 \%$ ) was prepared by dissolving an accurately weighed amount of capsaicin at the required concentration in polysorbate 80 . Capsaicin was solubilized with the aid of heat between 50 to $70^{\circ} \mathrm{C}$. Upon dissolution, $0.9 \%$ sodium chloride solution was added to the polysorbate solution to bring up the volume to the required batch size. The product was then sterilized by filtering through a $0.1 \mu \mathrm{m}$ Durapore PVDF membrane Millipak ${ }^{\circledR} 40$ (Millipore, Billerica, MA, USA) and aseptically filled into sterile amber borosilicate single-dose glass vials with a fill volume of $1.1 \mathrm{~g}$. Each vial was overlaid with sterile filtered nitrogen, sealed with a sterile rubber closure, and crimped. Specific gravity of the product was determined to be $1.0 \mathrm{~g} / \mathrm{mL}$.

\section{Sterility and Bacterial Endotoxin Testing}

Samples for sterility and Bacterial Endotoxin Testing (BET) were selected from the beginning, middle and the end of the fill process. Method suitability testing was conducted as part of sterility testing. Samples were provided to a referral analytical laboratory for this testing in accordance to USP Chapters $<71>$ and $<85>[24,25]$.

\section{Stability testing}

Stability testing of the product was conducted on the manufactured lot. Samples were randomly selected from the lot and placed in temperature controlled environments under refrigerated $\left(5^{\circ} \mathrm{C}\right)$ and ambient conditions $\left(25^{\circ} \mathrm{C}, 30^{\circ} \mathrm{C}\right)$. Each vial was collected from each temperature controlled environment at time points of one, three, six, and twelve months and subjected to physical and chemical stability testing. Additionally, a short term stability test at freezing conditions was performed for the product stored at freezer temperature $\left(-18^{\circ} \mathrm{C}\right)$ overnight (at least $12 \mathrm{~h}$ ). Product in the vials were thawed at ambient temperature and immediately evaluated for presence of precipitate or any abnormal occurrences using a validated HPLC method. Potency testing after $24 \mathrm{~h}$ was conducted on thawed vials stored at freezer $\left(-18^{\circ} \mathrm{C}\right)$ and at refrigerated $\left(5^{\circ} \mathrm{C}\right)$ conditions.

The physical characteristics of the solutions were evaluated qualitatively at each sampling point. Each sample was visually inspected without magnification for changes in color, clarity, particulate matter, and product/container closure abnormalities.

\section{Determination of potency}

The concentration of capsaicin solutions were measured by a modified Capsaicin USP HPLC method [26], by using a Waters HPLC
Alliance system on an e2695 separations module with a Waters 2998 Photo-Diode Array (PDA) detector (Waters Inc., Milford, MA, USA). Samples $(20 \mu \mathrm{L})$ were injected using a Waters auto injector and the instrument was controlled by use of Empower $2^{\circ}$ software (Waters Inc., Milford, MA, USA). Components were separated on a Nova-Pak ${ }^{\circledR} \mathrm{C} 18$ reversed-phase column (Waters Inc., Milford, MA, USA) with $150 \mathrm{~mm}$ $\times 3.9 \mathrm{~mm}$ dimensions and $5 \mu \mathrm{m}$ particle size. The column was kept thermostatic at $30^{\circ} \mathrm{C}$ in a Waters column oven (Waters Inc., Milford, MA, USA).

The HPLC system was calibrated for at least $30 \mathrm{~min}$ before determining the concentration of each stored capsaicin solution with the calibration curve developed with fresh capsaicin solutions of different concentrations. The percentage of Relative Standard Deviation (RSD) of the assay was determined to be $\pm 4 \%$, so we assumed any change in concentration greater than $4 \%$ was greater than the expected deviation due to the sensitivity of the HPLC system and assay itself. The concentration of each solution was analyzed in triplicate and the mean concentrations were recorded for each solution at the different time intervals. The Limit of Detection (LOD) and Limit of Quantification (LOQ) were determined by applying the following formula $[27,28]$;

$L O D=3.3 \sigma / m$

$L O Q=10 \sigma / \mathrm{m}$

where $\sigma$ is the standard deviation of the intercept of regression line, and $m$ is the slope of the calibration curve. The LOD and LOQ were found to be 0.2 and $0.6 \mu \mathrm{g} / \mathrm{ml}$ respectively with a RSD of less than $3 \%$.

\section{Statistical analysis}

A two-way ANOVA with interaction was used to analyze the percent change of capsaicin concentrations stored at $5^{\circ} \mathrm{C}, 25^{\circ} \mathrm{C}$ and $30^{\circ} \mathrm{C}$ at one, three, six, and twelve months. Subgroup analyses were carried out at each temperature (respectively at each time point) and each time point (respectively at each temperature) to determine interaction effects. The Mann-Whitney test was used in case of unrecognized non-normality due to small sample size. The statistical analysis was performed using SAS 9.3 (SAS Inc., Cary, NC).

\section{Results}

\section{Potency and stability}

Figure 1 depicts the percent change in concentration over time of capsaicin stored at the three environmental temperatures. The concentration of capsaicin in freshly manufactured solutions was found to be $104 \%$ of predicted. Product samples were found to be stable, between 90 to $110 \%$ of the labeled potency.

Percent change in concentration of capsaicin was found over time at $5^{\circ} \mathrm{C}(\mathrm{p}<0.0001), 25^{\circ} \mathrm{C}(\mathrm{p}=0.0012)$, and $30^{\circ} \mathrm{C}(\mathrm{p}<0.0001)$. Percent change in concentration was observed at 1 month $(\mathrm{p}<0.004), 3$ months $(\mathrm{p}<0.004)$ and 12 months $(\mathrm{p}<0.004)$, but it was not significantly changed at 6 months $(\mathrm{p}=0.896)$ (Table 1$)$.

Samples that underwent freeze thaw cycles showed no deviation from labeled potency. The change in concentration from pre-freeze to following freeze-thaw was $97.72 \pm 1.32(\mathrm{p}=0.0002)$ and the change in concentration after $24 \mathrm{~h}$ on thawed vials stored at freezer $\left(-18^{\circ} \mathrm{C}\right)$ was $90.47 \pm 0.10(\mathrm{p}=0.0002)$ and stored at refrigerated $\left(5^{\circ} \mathrm{C}\right)$ conditions was $103.48 \pm 0.70(\mathrm{p}=0.0002)$.

\section{Sterility and BET}

The product met the requirement of both sterility and BET tests in accordance to USP Chapters $<71>$ and $<85>[24,25]$. Samples were 


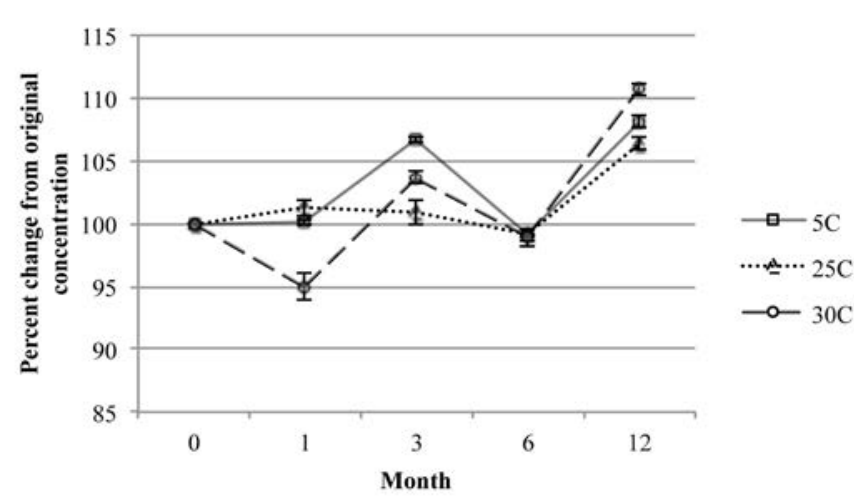

Figure 1: Percent change in concentration over time (in months) of capsaicin solutions stored at $5^{\circ} \mathrm{C}$ (squares), $25^{\circ} \mathrm{C}$ (triangles), and $30^{\circ} \mathrm{C}$ (circles). Data are presented as mean \pm SD.

\begin{tabular}{|c|c|c|c|}
\hline \multirow{2}{*}{ Time $^{* *}$} & \multicolumn{3}{|c|}{ Temperature $^{*}$} \\
\cline { 2 - 4 } & $5^{\circ} \mathrm{C}$ & $25^{\circ} \mathrm{C}$ & $30^{\circ} \mathrm{C}$ \\
\hline 1 month & $100.09 \pm 0.15$ & $101.22 \pm 0.61$ & $94.96 \pm 1.05$ \\
\hline 3 months & $106.64 \pm 0.17$ & $100.90 \pm 0.96$ & $103.64 \pm 0.48$ \\
\hline 6 months & $99.10 \pm 0.48$ & $99.07 \pm 0.18$ & $98.89 \pm 0.71$ \\
\hline 12 months & $108.10 \pm 0.50$ & $106.35 \pm 0.50$ & $110.72 \pm 0.50$ \\
\hline
\end{tabular}

*Percent change in concentration was observed at $5^{\circ} \mathrm{C}, 25^{\circ} \mathrm{C}$, and $30^{\circ} \mathrm{C}$ over the 12 month period $(p<0.001)$.

**Percent change in concentration was observed at 1 month, 3 months, and 12 months $(p<0.004)$.

Table 1: Percent change in capsaicin concentration (mean $\pm S D$ ) according to time and temperature.

sterile and free from bacterial endotoxins. Visual examination of samples at each time point showed no evidence of any change in color or clarity or the presence of particulate matter.

\section{Discussion}

Attempts have been made to improve the sensitivity of the capsaicin model of allodynia and hyperalgesia by reducing sources of variability. Although a clear relationship has been established between dose and pain response $[4,18,20]$, the potency and stability of prepared capsaicin solutions has not been examined in human pain models. Ensuring the accuracy of capsaicin concentrations is as crucial as controlling for other sources of variability, including dose $[1,4,18,20,21]$, formulation [18], administrative route [17-19], and injection site $[17,18]$ if it is to serve as an effective biomarker for underlying pain mechanisms and treatment response.

Capsaicin contained $104 \%$ of the labeled potency in freshly manufactured solutions. The difference between the predicted concentrations and the actual concentrations are comparable to Kopec's first study (88\% of predicted) [22] and higher than the second (69-83\% of predicted) [23]. Our increased accuracy may be due to the use of polysorbate 80 (Tween 80 ) to improve capsaicin solubility, as Kopec found actual concentrations were higher in solutions containing this emulsifier compared to those without this ingredient [23]. Differences may also be due to minor differences in assay methods or preparation procedures between laboratories.

Although our drug stability data showed statistically significant differences over time, the 90 to $110 \%$ range in concentrations observed were within the Food and Drug Administration's allowable guidelines of $100 \pm 10 \%$ [29] at all time points (1 month: 95-101\%, 3 months: 101-107\%, 6 months: $98-99 \%$, and 12 months: 106-110\%) in samples protected from light. These results are similar to those reported by Kopek for refrigerated samples protected from light (2 months: 104\%, 4 months: $108 \%$, 6 months: $109 \%, 8$ months: $110 \%$, 10 months: $106 \%$, and 12 months: $90 \%)$.

Although Kopek found solutions to meet $90 \%$ of labeled potency with refrigeration (90-110\%) and at higher concentrations (95-110\%), solutions stored at room temperature whether or not exposed to light (20-100\%) and solutions at lower concentrations (60-100\%) were not stable [22,23]. Similar to Kopek, we observed significantly different changes in concentration at varying temperatures, but unlike Kopek, they remained within the FDA guidelines at all temperatures $\left(5^{\circ} \mathrm{C}: 99\right.$ $108 \%, 25^{\circ} \mathrm{C}: 99-106 \%$, and $\left.30^{\circ} \mathrm{C}: 95-110 \%\right)$ and differences were not uniformly found at higher temperatures. We also found that samples undergoing short freeze thaw cycles showed no significant deviation from labeled potency, while Kopec found that frozen solutions degraded after 1 year $[22,23]$. It is possible that long term freezing of solutions disrupts the structure of capsaicin during the freezing process or during re-warming. Further short-term and long-term studies are warranted.

The temperature-dependent effects in Kopec's study may be due to the lower concentrations used (up to $0.004 \%$ solution), as capsaicin was being tested for aerosol administration rather than for intradermal administration. The higher concentrations used in our study $(0.1 \%$ capsaicin solution) are those commonly used in intradermal pain studies, and may be more stable over time, since the chemical may aggregate to form more stable complexes and is thus less likely to precipitate out [22]. It is unlikely that our use of polysorbate 80 was contributory since even though Kopec found that the emulsifier improved the accuracy of initial concentrations, it did not prevent product degradation [23].

Our formulation provides a useful intradermal capsaicin model because it maintains its potency and stability for twelve months when stored at $5^{\circ} \mathrm{C}, 25^{\circ} \mathrm{C}$ and $30^{\circ} \mathrm{C}$ in an environment protected from light. The stability of capsaicin solution during freeze thaw cycles indicates it could be safely transported in a frozen state. Centralized manufacturing capsaicin solution, for each study site provides important product uniformity and quality control across a multicenter effort. These findings suggest that centralized manufacturing may be an effective and convenient way to provide capsaicin intradermal injection to assess pain and analgesic efficacy in multicenter trials. Stability studies are continuing in order to replicate our current findings over longer testing periods.

\section{Acknowledgement}

The authors would like to thank the National Institutes of Health for awarding the grant (USPHS Grant \# HD-065740-01) for conducting the study and to Leslie A. Rawlinson for administrative support.

\section{References}

1. Culp WJ, Ochoa J, Cline M, Dotson R (1989) Heat and mechanical hyperalgesia induced by capsaicin. Cross modality threshold modulation in human C nociceptors. Brain 112: 1317-1331.

2. LaMotte RH, Lundberg LE, Torebjörk HE (1992) Pain, hyperalgesia and activity in nociceptive $C$ units in humans after intradermal injection of capsaicin. $J$ Physiol 448: 749-764.

3. LaMotte RH, Shain CN, Simone DA, Tsai EF (1991) Neurogenic hyperalgesia psychophysical studies of underlying mechanisms. J Neurophysiol 66: 190-211.

4. Simone DA, Baumann TK, LaMotte RH (1989) Dose-dependent pain and mechanical hyperalgesia in humans after intradermal injection of capsaicin. Pain 38: 99-107.

5. Sluka KA, Willis WD (1997) The effects of G-protein and protein kinase inhibitors 
Citation: Balabathula P, Bhattacharjee H, Thoma LA, Nolly RJ, Horton FP, et al. (2013) Potency and Stability of Intradermal Capsaicin: Implications for Use as a Human Model of Pain in Multicenter Clinical Trials. Clin Exp Pharmacol 3: 142. doi:10.4172/2161-1459.1000142

on the behavioral responses of rats to intradermal injection of capsaicin. Pain 71: 165-178.

6. Caterina MJ, Schumacher MA, Tominaga M, Rosen TA, Levine JD, et al. (1997) The capsaicin receptor: a heat-activated ion channel in the pain pathway. Nature 389: 816-824.

7. Lynn B (1990) Capsaicin: actions on nociceptive C-fibres and therapeutic potential. Pain 41: 61-69.

8. Petersen KL, Fields HL, Brennum J, Sandroni P, Rowbotham MC (2000) Capsaicin evoked pain and allodynia in post-herpetic neuralgia. Pain 88: 125133.

9. Sieweke N, Birklein F, Riedl B, Neundörfer B, Handwerker HO (1999) Patterns of hyperalgesia in complex regional pain syndrome. Pain 80: 171-177.

10. Morris V, Cruwys S, Kidd B (1998) Increased capsaicin-induced secondary hyperalgesia as a marker of abnormal sensory activity in patients with fibromyalgia. Neurosci Lett 250: 205-207.

11. Staud R, Vierck CJ, Cannon RL, Mauderli AP, Price DD (2001) Abnorma sensitization and temporal summation of second pain (wind-up) in patients with fibromyalgia syndrome. Pain 91: 165-175.

12. Morris VH, Cruwys SC, Kidd BL (1997) Characterisation of capsaicin-induced mechanical hyperalgesia as a marker for altered nociceptive processing in patients with rheumatoid arthritis. Pain 71: 179-186.

13. Foster DC, Dworkin RH, Wood RW (2005) Effects of intradermal foot and forearm capsaicin injections in normal and vulvodynia-afflicted women. Pain 117: 128-136.

14. Aykanat V, Gentgall M, Briggs N, Williams D, Yap S, et al. (2012) Intradermal capsaicin as a neuropathic pain model in patients with unilateral sciatica. $\mathrm{Br} J$ Clin Pharmacol 73: 37-45.

15. Holst $\mathrm{H}$, Arendt-Nielsen L, Mosbech H, Elberling J (2011) Increased capsaicininduced secondary hyperalgesia in patients with multiple chemical sensitivity. Clin J Pain 27: 156-162.

16. Yunus MB (2008) Central sensitivity syndromes: a new paradigm and group nosology for fibromyalgia and overlapping conditions, and the related issue of disease versus illness. Semin Arthritis Rheum 37: 339-352.
17. Liu M, Max MB, Robinovitz E, Gracely RH, Bennett GJ (1998) The human capsaicin model of allodynia and hyperalgesia: sources of variability and methods for reduction. J Pain Symptom Manage 16: 10-20.

18. Gustafsson H, Akesson J, Lau CL, Williams D, Miller L, et al. (2009)A comparison of two formulations of intradermal capsaicin as models of neuropathic pain in healthy volunteers. Br J Clin Pharmacol 68: 511-517.

19. Hughes A, Macleod A, Growcott J, Thomas I (2002) Assessment of the reproducibility of intradermal administration of capsaicin as a model for inducing human pain. Pain 99: 323-331.

20. Scanlon GC, Wallace MS, Ispirescu JS, Schulteis G (2006) Intraderma capsaicin causes dose-dependent pain, allodynia, and hyperalgesia in humans. J Investig Med 54: 238-244.

21. Sikand P, Shimada SG, Green BG, LaMotte RH (2011) Sensory responses to injection and punctate application of capsaicin and histamine to the skin. Pain 152: $2485-2494$

22. Kopec SE, DeBellis RJ, Irwin RS (2002) Chemical analysis of freshly prepared and stored capsaicin solutions: implications for tussigenic challenges. Pulm Pharmacol Ther 15: 529-534.

23. Kopec SE, Irwin RS, Debellis RJ, Bohlke MB, Maher TJ (2008) The effects of Tween-80 on the integrity of solutions of capsaicin: useful information for performing tussigenic challenges. Cough 4: 3 .

24. USP (2011) Sterility Tests. (34thedn), USP: Rockville 1: 65-70.

25. USP (2011) Bacterial Endotoxins Test. (34thedn), USP: Rockville 1: 78-81.

26. USP (2011) Capsaicin USP. (34thedn), USP: Rockville 1: 2151-2152.

27. Balabathula P, Janagam DR, Mittal NK, Mandal B, Thoma LA, et al. (2013) Rapid Quantitative Evaluation of Amphotericin B in Human Plasma, by Validated HPLC Method. J Bioequiv Availab 5: 121-124.

28. Mandal B, Balabathula P, Mittal N, Wood GC, Bhattacharjee H (2012) Development and validation of a spectrofluorimetric method for the determination of erlotinib in spiked human plasma. J Fluoresc 22: 1425-1429.

29. FDA (2008) Guidance for Industry, Drug Stability Guidelines, ed. FDA. US Department of Health and Human Services. 